\title{
Early treatment of coronal synostosis with endoscopy-assisted craniectomy and postoperative cranial orthosis therapy: 16-year experience
}

\author{
Clinical article
}

\author{
David F. Jimenez, M.D., and Constance M. Barone, M.D. \\ Department of Neurosurgery, The University of Texas Health Science Center at San Antonio, Texas
}

\begin{abstract}
Object. The objective of this study was to present the authors' 16-year experience treating coronal craniosynostosis in infants using endoscopy-assisted techniques and postoperative cranial orthoses.

Methods. A total of 128 synostosed coronal sutures in 115 patients were treated between 1996 and 2012 by endoscopically resecting a strip of bone containing the stenosed suture via a $2-3 \mathrm{~cm}$ incision made at the ipsilateral stephanion. Data were obtained from a prospective database. Following surgery, patients were fitted with custom cranial orthoses to help correct preoperative craniofacial deformities. All patients were followed closely with cranial anthropometric measurements and photographs.

Results. The estimated mean blood loss was $20 \mathrm{ml}$ (range 5-120 ml) and the estimated mean strip size was $0.6 \mathrm{~cm} \times 10.7 \mathrm{~cm}$. The mean surgical duration was 55 minutes (range 22-150 minutes). One patient underwent an intraoperative blood transfusion and 1 had a postoperative blood transfusion, for a total transfusion rate of $1.7 \%$. Ninety-seven percent of patients were discharged on the first postoperative day. There were no deaths. Vertical dystopia correction of more than $80 \%$ from baseline was obtained in almost two-thirds of patients, with $51 \%$ achieving $100 \%$ correction. Nasal and sagittal craniofacial deviation (vertex-nasion-gnathion) correction greater than $80 \%$ was achieved in $80 \%$ of patients, with $77 \%$ achieving $100 \%$ correction. Supraorbital rim advancement of the ipsilateral eye was obtained in $98 \%$ of cases, with correction of frontal plagiocephaly the last deformity to achieve correction.

Conclusions. Early treatment of coronal synostosis with endoscopy-assisted craniectomy and postoperative molding helmets leads to significant correction of craniofacial abnormalities, including vertical dystopia, nasal deviation, sagittal misalignment, and ipsilateral proptosis. This treatment method is associated with minimal trauma, blood loss, and transfusion rates, and typically only requires 1 overnight stay. This surgical approach is safe, effective, and associated with excellent results.

(http://thejns.org/doi/abs/10.3171/2013.4.PEDS11191)
\end{abstract}

$\begin{array}{llll}\text { KEY Words } & \bullet \text { craniosynostosis } \bullet \text { coronal } \bullet \text { craniectomy } \bullet & \text { endoscopy } \\ \text { helmet } \bullet \text { plagiocephaly } \bullet \text { functional neurosurgery }\end{array}$

A PPROPRIATE surgical management of patients with coronal synostosis presents the treating craniofacial surgeon and neurosurgeon with a significant challenge, given the marked deformational changes that are produced and ultimately affect the craniofacial skeleton. Many techniques have been used over the years with varying degrees of success. ${ }^{22,23,30}$ During the past several decades, the standard way of treating these patients involves the use of extensive calvarial vault remodeling techniques. Most commonly, both frontal bones are removed via bifrontal craniotomies, along with bilateral elevation of the orbital bandeau, which may extend below the ipsilateral frontozygomatic suture. The affected side is typically advanced over several centimeters in a tongue-in-groove fashion to obtain symmetry. ${ }^{26}$ Although this method is technically rewarding and shows excellent initial results, a review of our personal case series (and that of other surgeons) led us to the conclusion that results with this method are suboptimal over time. When patients are treated later ( $>9$ months of age), the skull base changes that occur such as vertical dystopia, craniofacial scoliosis, and nasal deviation are not adequately treated with these extensive techniques. The simple removal and repositioning of the supraorbital rim does nothing to correct the medial, inferior, and lateral walls of the dystopic orbit. In an effort to better address these deformational changes we have introduced the concept of minimally invasive, endoscopy-assisted suture osteotomies in young infants, followed by cranial molding using cranial orthoses. Although we have previously published 


\section{F. Jimenez and C. M. Barone}

on this subject ${ }^{1,10-16,30}$ in a preliminary fashion and with short-term results, our goals with this paper are to present an in-depth and long-term analysis of using this surgical approach during the last 16 years in young infants with coronal craniosynostosis.

\section{Methods}

\section{Study Population}

Between 1996 and 2012, a total of 115 patients who presented with coronal craniosynostosis were treated with endoscopy-assisted craniectomies of the involved sutures. There were 65 girls (57\%) and 50 boys (43\%). The patients' ages ranged between 36 weeks' gestation to 10 months (mean 3.1 months, median 2.9 months). The mean weight of the patients was $6.4 \mathrm{~kg}$ (median $6.2 \mathrm{~kg}$, range $2.9-10 \mathrm{~kg}$ ). The right coronal suture was affected $71.3 \%$ of the time $(\mathrm{n}=82)$ while the left side was affected $28.7 \%$ $(n=33)$. Sixty-five percent of the cases of right coronal synostosis were females $(n=57)$ and $35 \%$ were males $(n$ $=28$ ). Fifty-seven percent of the cases of left coronal synostosis were males $(n=17)$ whereas $43 \%$ where females $(n=13)$. The only preoperative serum value obtained was a single heel-stick, spun hematocrit level following anesthesia induction. The endoscopes used consisted of 4-mm rigid $0^{\circ}$ and $30^{\circ}$ rod-lens scopes (Karl Storz). The size of the bone strip removed was a mean length of 10.7 $\mathrm{cm}$ (range 5-13 cm; Table 1), and extended the distance between the anterior fontanelle and the squamosal suture. The mean width of the removed bone strip was $0.6 \mathrm{~cm}$ (range $0.3-2 \mathrm{~cm}$ ); in 55 patients the width was $0.5 \mathrm{~cm}$ or less.

\section{Anesthesia Procedure}

After preoperative evaluation, the patient was taken to a heated operating suite and placed on the operating table. Standard anesthesia monitors were placed such as an electrocardiogram, noninvasive blood pressure monitor, and 2 pulse oximetry probes, which was done to insure constant oxygen saturation and pulse rate monitoring throughout the surgical procedure. Induction was accomplished by inhalation of a high concentration of

\section{TABLE 1: Summary of results*}

\begin{tabular}{lc}
\hline \multicolumn{1}{c}{ Variable } & Mean (range) \\
\hline estimated blood loss $(\mathrm{ml})$ & $20(5-120)$ \\
estimated blood volume loss $(\%)$ & $3.7(1-27)$ \\
surgical duration $(\mathrm{min})$ & $55(22-150)$ \\
length of stay (days) & $1.02(1-3)$ \\
maximum body temperature $\left({ }^{\circ} \mathrm{C}\right)$ & $37.2(36.8-38.6)$ \\
craniectomy width $(\mathrm{cm})$ & $0.6(0.3-2)$ \\
craniectomy length $(\mathrm{cm})$ & $10.7(5-13)$ \\
preop hematocrit $(\%)$ & $31.7(25-40)$ \\
PACU hematocrit $(\%)$ & $28.5(18-38)$ \\
postop Day 1 hematocrit $(\%)$ & $27.6(17-36)$ \\
\hline
\end{tabular}

* PACU = postanesthesia care unit. sevoflurane with oxygen and nitrous oxide. A preoperative (heel-stick) hematocrit level was obtained at the time of the intravenous cannulation. Muscle relaxation was obtained with rocuronium given at a $600 \mathrm{mcg} / \mathrm{kg}$ dose. Because of the short duration of the surgical procedure, a further muscle relaxant was usually unnecessary. Intubation was performed with a size-appropriate endotracheal tube under direct laryngoscopy. Careful attention was paid to securing the endotracheal tube because the patient was eventually rotated $180^{\circ}$ from the anesthesia machine. Equal breath sounds were confirmed immediately after intubation, after securing the tube, and the final positioning of the patient.

An antibiotic, usually cefazolin given at a $40-60 \mathrm{mg} /$ $\mathrm{kg}$ dose, was administered intravenously along with 1-2 $\mathrm{mcg} / \mathrm{kg}$ of fentanyl prior to the start of the surgical procedure. Rectal acetaminophen (10-15 mg/kg) was administered to help with postoperative pain control. Maintenance of core body temperature is critical in pediatric patients and the operating room was prewarmed before the surgery and kept warm throughout the procedure. Warming lights and warm air blankets were used to maintain patient temperature throughout the surgery. Anesthesia was maintained throughout the procedure with sevoflurane, oxygen, and additional fentanyl as indicated. Maintenance intravenous fluids were delivered warmed. Additional fluid boluses were usually not indicated given the minimal blood loss and short duration of the procedure.

At the completion of the surgery, a postoperative hematocrit level was obtained to assess and estimate blood loss. Anesthetic agents were discontinued and muscle relaxant reversal agents were administered as necessary. Additional fentanyl and morphine were administered as needed for pain. Extubation was performed after the patient met standard awake extubation criteria. The patient was then transported to the postoperative care unit with supplemental oxygen and standard monitors.

\section{Surgical Procedure}

Peripheral intravenous access was achieved using 1 or 2 lines and no arterial or central venous lines were used. The patient was placed supine with the head resting on a cerebellar headrest. Corneal protectors with ophthalmic ointment were used and the surgical field was prepared with Betadine scrub and paint. The surgical procedure consisted of a $2-$ to $3-\mathrm{cm}$ incision located behind the hairline at the level of the ipsilateral stephanion (junction of the coronal suture and superior temporal crest; Fig. 1). Monopolar electrocautery (needle tip) set at $15 \mathrm{~W}$ was used to cut the scalp and develop the subgaleal dissection plane. Using a rhinoplasty lighted retractor, the subgaleal dissection was first directed medially toward and up to the anterior fontanelle and then laterally toward the ipsilateral pterion. A pediatric craniotome, with a $7-\mathrm{mm}$ perforator, was used to make a single bur hole at the incision. Kerrison rongeurs $(6 \mathrm{~mm})$ were used to enlarge the bur hole toward the anterior fontanelle and the pterion. Hemostasis was easily obtained using Surgiflo (Johnson and Johnson) and liquid Thrombin (Gen Trac, Inc.). The $30^{\circ}$ rigid endoscope was inserted under the bone and directed toward the anterior fontanelle and handled with 


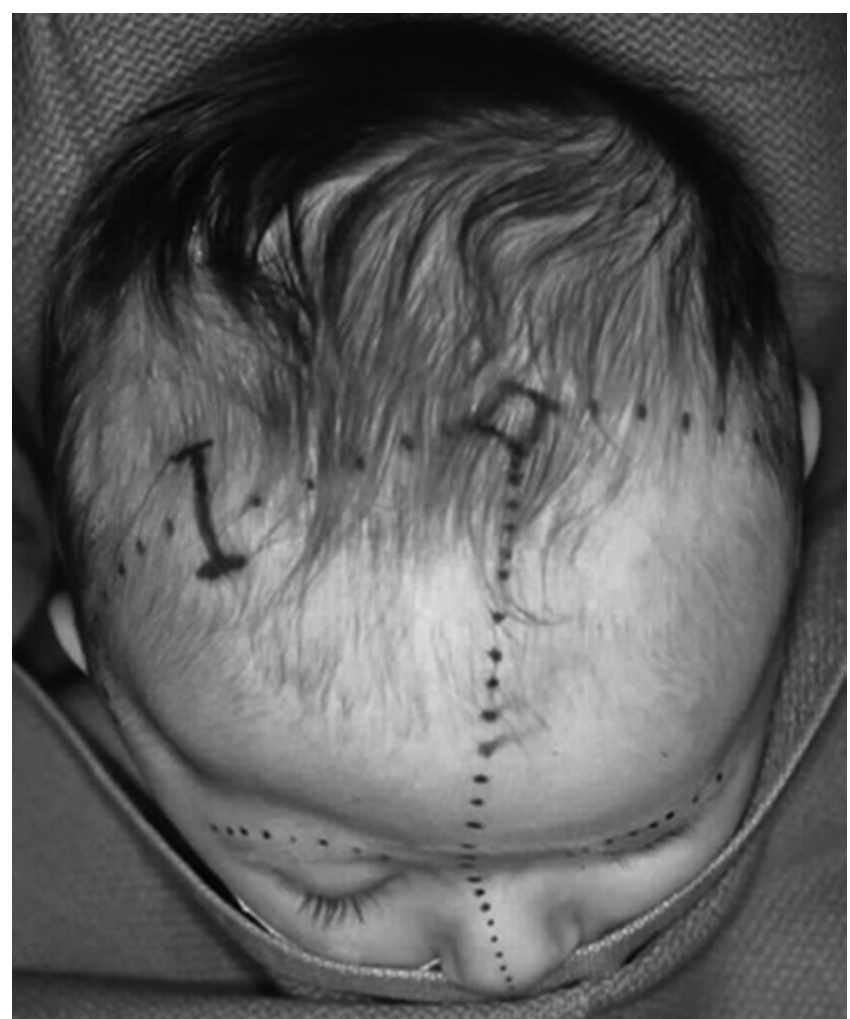

FIG. 1. Photograph showing location of the incision, measuring 2.5 $\mathrm{cm}$. The incision is placed on the right side approximately halfway between the anterior fontanelle and the pterion. Dissection in this patient is being extended toward the squamosal suture.

the surgeon's dominant hand. A small (7 Fr) blunt-tipped, insulated suction tube was used to dissect the dura away from the overlying bone as well as to keep the endoscopic visual field clear and bloodless. The endoscope and suction tube were advanced and moved in tandem up to the adherent fibers at the level of the anterior fontanelle. Once the bone was separated from the scalp and dura, curved Mayo or bone-cutting scissors were used to cut a wedge of bone containing the stenosed suture. The medial-most aspect of the osteotomy, next to the anterior fontanelle, was made using pituitary rongeurs. Care was taken not to disrupt the dural attachment to the fontanelle and thereby risk injury to the sagittal sinus. Complete release of the frontal bone was ascertained by gently pushing the scalp over the bone and observing free and unrestricted movement of both edges of the frontal and parietal bones on the TV monitor.

Next, attention was directed to dissection of the epidural space toward the pterion and the ipsilateral squamosal suture. The suction and endoscope were advanced toward the ipsilateral pterion under the stenosed coronal suture, which often presents with a small prominent ridge. The lesser wing of the sphenoid can be easily identified at this point, as well as branches of the middle meningeal artery. Typically the inferior-most aspect of the coronal suture is open and the interdigitating dural fibers can be used to identify this area. The endoscope was advanced posterior to the open-end coronal suture. The operating room lights were turned off and illumination (with the $30^{\circ}$ endoscope) across the bone and soft cutaneous tissue was used to mark the skin over the squamosal suture. A pair of Mayo or bone-cutting scissors was then used to sequentially cut an osteotomy, extending from the bur hole to the squamosal suture, posterior to the open and inferior-most aspect of the coronal suture (Fig. 2). Final hemostasis of the exposed diploic space was obtained with the use of a suction electrocautery unit (Valley Lab) set at $60-\mathrm{W}$ coagulation mode. The galea and the underlying dura were protected using insulated flexible brain retractors. The bone edges were continuously cauterized until all bleeding stopped, often requiring multiple passes. Prior to closure, the dura was inspected for tears and a Valsalva maneuver was used to identify any CSF leaks. The incision was infiltrated with $0.25 \%$ bupivacaine without epinephrine at a dose of $1 \mathrm{ml} / \mathrm{kg}$. Absorbable 4-0 Monocryl sutures (Ethicon) were used for galeal closure and Dermabond (Ethicon) was used for dermal closure.

\section{Postoperative Orthoses}

The use of helmets, albeit time and effort consuming, plays a critical role in obtaining excellent results following osteotomies and cranial release. Typically, on the fourth postoperative day, the patient's head is scanned with a proprietary infrared beam STARscanner (Orthomerica Products, Inc.) and a custom-made helmet is manufactured and delivered on the 6th postoperative day. The helmets are manufactured with the commercially available resin Surlyn (Dupont), which is a thermoplastic ionomer resin and is the random copolymer poly (ethylene-comethacrylic acid). Its physical properties make it an ideal material for molding cranial helmets. The overall helmet shell is made of Surlyn and the inner padding is made of an ethylene acetate lining. Extra space was placed over the retracted ipsilateral frontoorbital complex (Fig. 3). Reston foam stabilizer pads (3M) are also

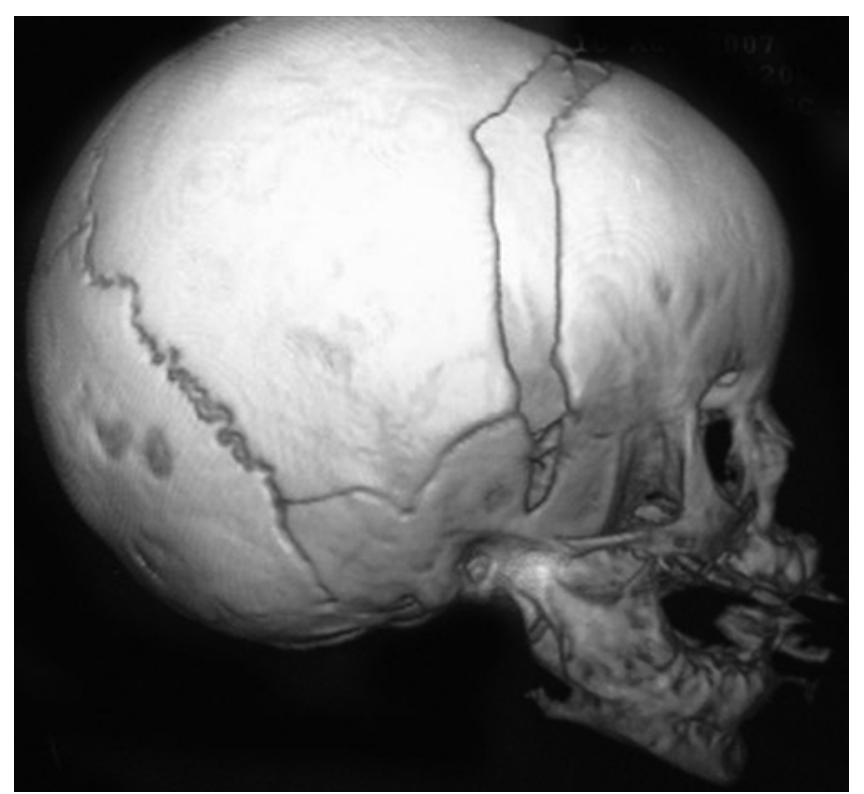

FIG. 2. Postoperative 3D CT scan demonstrating the extent of bone resection that extends from the anterior fontanelle to the squamosal suture. The osteotomy is created posterior to the stenosed coronal suture. 


\section{F. Jimenez and C. M. Barone}

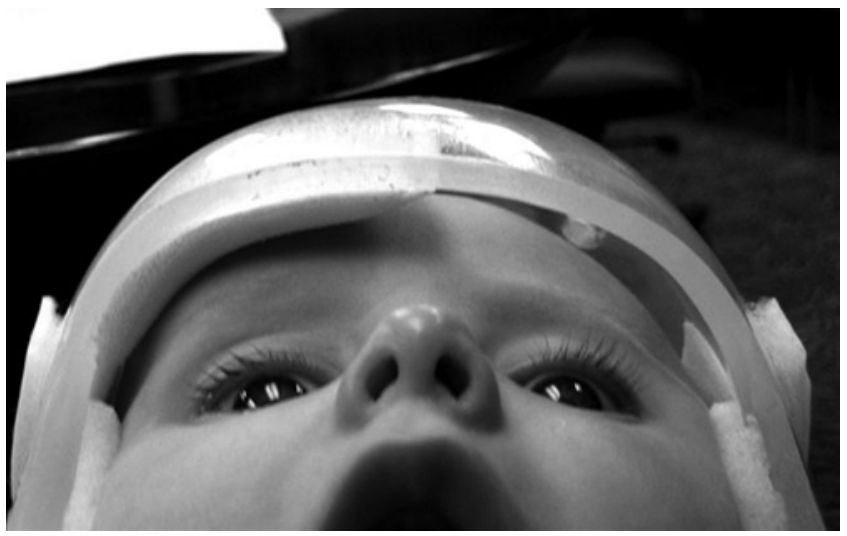

Fig. 3. Submental vertex view of patient with left coronal synostosis wearing helmet one week after surgery. Note padded area over the right frontal area and extra space over left frontal area to allow for expansion and correction of left frontal plagiocephaly.

used to keep the helmet from inappropriately shifting. To standardize the manufacturing process, the patient's head is scanned locally and the digital data are sent to a central manufacturing center (Orlando, Florida) where a computer-assisted process allows for the creation of a custom-made helmet, set to the surgeon's specifications. The helmet was to be worn incrementally beginning on postoperative Day 6 until ultimately achieving a daily usage schedule of 22-23 hours per day within a week. Any other areas of calvarial asymmetry, as noted in patients with concomitant torticollis and posterior plagiocephaly, were also properly addressed with the helmet. If areas of redness persisted for more than 30 minutes after removal of the helmet, appropriate adjustments to the helmet and wearing schedule were made to prevent skin breakdown.

\section{Anthropometric Data}

Cranial anthropometric data were collected preoperatively and during all subsequent postoperative visits. Anthropometric points consisted of opisthocranion to glabella; euryon to euryon, and calculated cephalic index; opisthocranion to right frontozygomaticus; opisthocranion to left frontozygomaticus; left midoccipital to right frontozygomaticus; and right midoccipital to left frontozygomaticus. Standard anteroposterior photographs were obtained preoperatively and at every postoperative visit. To quantitate the amount of vertical dystopia, a line was drawn (line A) from the exocanthion, through the mid pupil, to the endocanthion of the eye contralateral to the synostosis. The line was extended across the face and the distance from the midpupil (of the eye ipsilateral to the synostosis) to Line A was measured in millimeters. This measurement was considered the amount of orbital elevation and displacement (Fig. 4 left). To quantitate the amount of craniofacial deviation from the sagittal plane, a line was drawn from the nasion to the gnathion through the labiale superius. A second line was drawn from the nasion to the vertex through the ophryon, and an angle was measured from the deviation of lines A and B and considered a measurement of craniofacial sagittal deviation (Fig. 4 right). Overhead photographs of the top of the head and STARscanner images (Fig. 5) were obtained to assess for amounts of supraorbital rim recession and ocular proptosis. All measurements were obtained by independent observers and analyzed by the institutional biostatistics department. All data were prospectively collected and risk factors analyzed; these risk factors included blood loss, length of stay, length of procedure, parenchymal or venous injuries, dural tears, hematomas, infections, venous air embolisms, deaths, need for reoperation, CSF leaks, coagulopathies, and need for ventriculoperitoneal shunt placements.

\section{Results}

A total of 115 patients underwent successful operations without any deaths, over a 16 -year period with a mean follow-up of 7.7 years (range 6 months to 12 years). The mean operative duration was 55 minutes (range 22-150 minutes; Table 1). The patients with longer operative durations also had multiple-suture synostosis $(n=12)$. Ninety-seven percent of the patients were hospitalized overnight and were discharged on the first postoperative morning. The mean estimated blood loss was $20 \mathrm{ml}$ (range 5-120 ml). Likewise, patients with higher blood loss also had multisuture involvement $(\mathrm{n}=12)$. These patients presented with nonsyndromic bicoronal craniosynostosis. All patients with classic syndromic bicoronal synostosis (Apert, Carpenter, and Crouzon syndrome, and others) were excluded from this work. The mean estimated percentage of blood volume loss was $3.7 \%$ (range 1\%-27\%); only 1 patient required a blood transfusion intraoperatively $(60 \mathrm{ml})$ and 1 patient postoperatively $(100 \mathrm{ml})$, for an overall transfusion rate of $1.7 \%$. Hematocrit levels were obtained immediately before the start of the procedure, at the end of the procedure, and the morning of the first postoperative day. The mean preoperative hematocrit level was $31.7 \%$, mean postoperative hematocrit was $28.5 \%$, and mean postoperative Day 1 hematocrit was $27.6 \%$ (Table 1 ).

Review of risk factors and complications showed that there were no patients who experienced infections, sagittal sinus injury, postoperative hematomas, visual or ocular injuries, seizures, conversion to open procedures, or deaths. Any venous air embolisms that occurred were classified according to the following definitions: Class I, change in Doppler tones; Class II, change in Doppler tones, decrease in end-tidal carbon dioxide, and no changes in blood pressure or oxygenation; and Class III, decrease in systolic blood pressure by $20 \%$ from baseline. ${ }^{30}$ Two patients experienced Class II venous air embolisms that had no clinical significance and did not affect the patients or the surgery. Two patients had dural tears, 1 small $(5 \mathrm{~mm})$ and the other larger $(1.5 \mathrm{~cm})$. The latter tear was associated with a minor parenchymal breach that did not result in a parenchymal hematoma or contusion. Both patients with dural tears developed subgaleal CSF collections. One collection resolved after removal of $60 \mathrm{ml}$ of CSF using a spinal tap, and the second required direct closure along with the use of Duragen (Integra Life Sciences) and fibrin glue. There were no transcutaneous CSF leaks. Two patients developed minor scalp irritations that were successfully treated by discontinuing helmet use for 5 days. Early in the series 3 patients developed small $(<1$ 


\section{Endoscopy-assisted treatment of coronal synostosis}
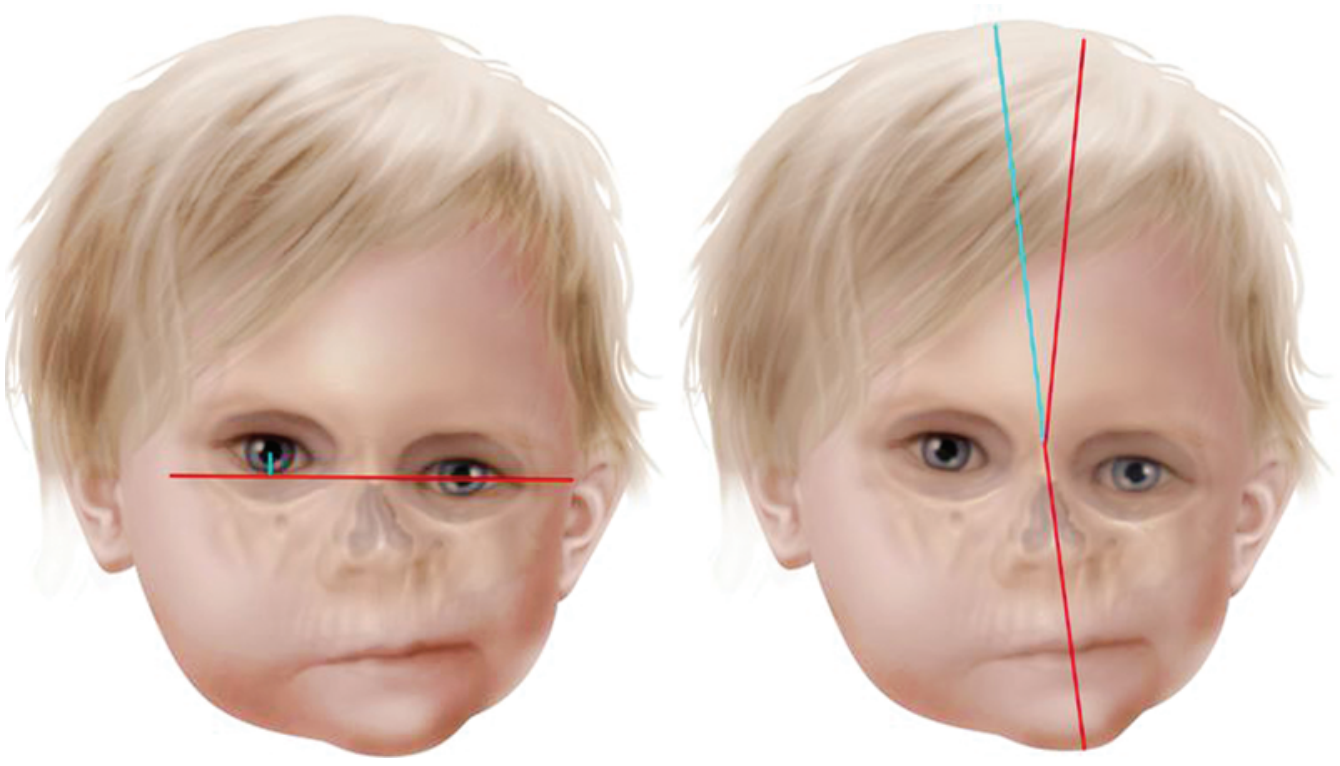

FIG. 4. Illustrations depicting the measurements used for vertical systopia (left) and sagittal plane craniofacial deviation (right). Left: A red line is drawn from the left exthocanthion to left endocanthion (bisecting the left pupil) and extended across the right side. The distance (blue line) from the mid right pupil to the red line is measured in millimeters and considered the amount of orbit elevation and dystopia of the affected right side. Right: A red line is drawn from the gnathion to the nasion, through labium superius, and extending to the vertex through the ophryon. An angle is measured between the extended blue line and the red line, representing the amount of sagittal plane deviation.

$\mathrm{cm})$ calvarial defects along the craniectomy site. In both cases, the osteotomies were between 1 and $2 \mathrm{~cm}$ in size. One calvarial defect developed in a patient, with the size of the osteotomy approximately $0.6 \mathrm{~cm}$.

\section{Vertical Dystopia}

One hundred five patients $(97 \%)$ presented with vertical dystopia and elevation of the ipsilateral orbit on the side of the coronal synostosis. An attempt to quantify the amount of dystopia was made by drawing a line from the exocanthus to the endocanthus of the uninvolved eye through the midpupil (Fig. 4 left). The line was extended to the contralateral eye and the distance from the midpupil to the line was measured in millimeters. This distance was considered the amount of vertical dystopia present at the time of measurement. A line bisecting both midpupils was an indication of normally positioned eyes and the absence of dystopia, or $100 \%$ correction over baseline following

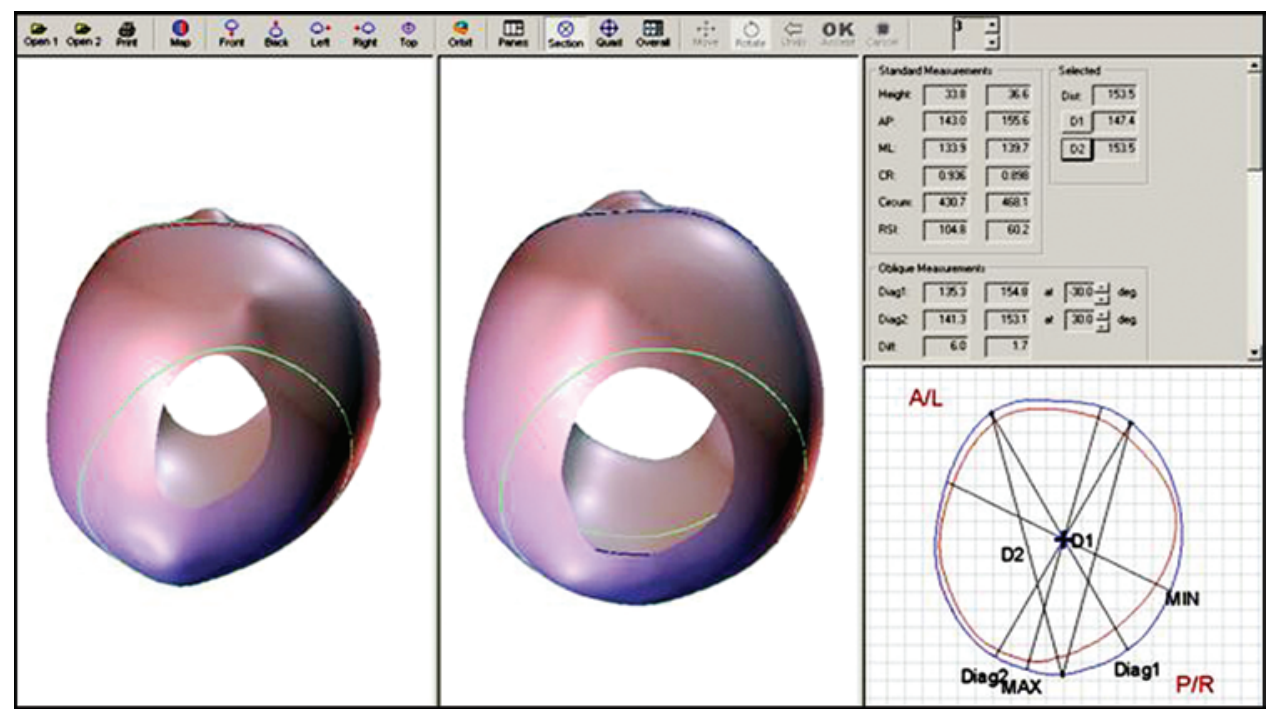

FIG. 5. STARscanner data, and $2 \mathrm{D}$ and $3 \mathrm{D}$ images of a patient with right coronal synostosis and right posterior plagiocephaly secondary to positional molding. The preoperative image is on the left. A 7-month postoperative image on the right shows improvement of both deformities and normalization of the calvarial shape. Right lower-corner image shows anthropometric measurements and preoperative (red outline) and postoperative (blue outline) 2D shapes; actual values are listed in the table in the upper right corner. 


\section{F. Jimenez and C. M. Barone}

surgery. Fifty-one percent of the patients obtained $100 \%$ correction of the dystopia present preoperatively; correction between $90 \%$ and $99 \%$ was obtained in $8.9 \%$ of patients, and correction between $80 \%$ and $89 \%$ was achieved in $5.1 \%$ of patients (Fig. 6). Consequently, we found that $65 \%$ of our patients had achieved greater than $80 \%$ correction of their dystopia (Fig. 7). The lowest amount of correction achieved was 38\%. Patients with less than $50 \%$ correction were all older than 8 months of age.

\section{Sagittal Plane Deviation}

Unilateral coronal synostosis commonly leads to cranial vault angulation and deviation from the sagittal plane. To quantify the amount of sagittal misalignment, en-face photographs and standard standard anteroposterior radiographs were used with lines drawn from the vertex through the nasion and extending to the gnathion and over the midphiltrum (Fig. 4 right). In a normal child, the line through all 3 points is a straight line. When midsagittal deviation is present, an angle is formed with the vertex of the angle located at the nasion. One ray is formed by the nasion-to-vertex line and the second ray is the continuation of a straight line of the nasion-to-gnathion line. Preoperative and postoperative photographs at all visits were measured. A $0^{\circ}$ angle (straight line) was considered $100 \%$ correction (Fig. 8). Seventy-four patients (81\%) presented with deviation of the cranial vault and face from the midsagittal plane. Over the period of the study, $100 \%$ correction of preoperative sagittal deviation was achieved in $77 \%$ of the patients $(n=84)$, correction between $80 \%$ and $90 \%$ was achieved in $4 \%$ of patients, and $70 \%$ correction was obtained in $7 \%$ of patients (Fig. 9). Patients with less than $70 \%$ correction comprised $12 \%$ of the patients, and these patients were also noted in the group older than 8 months of age.

\section{Frontal Asymmetry Correction}

Using anthropometric measurement and landmarks, the amount of frontal cranial asymmetry and level of correction was ascertained in all patients. Measurements were made with calipers and corroborated with data obtained from the STARscanner of the distance between the opisthocranion and right and left frontozygomaticus, re-

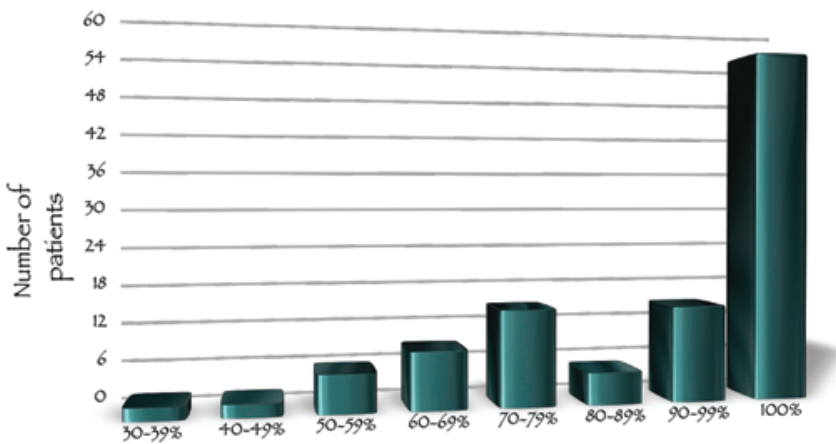

FIG. 6. Histogram showing the total number of patients who achieved different levels of correction of the preoperative vertical dystopia. One hundred percent correction means that the eyes were perfectly aligned in the horizontal plane and a single line bisected both endocanthi and exocanthi.
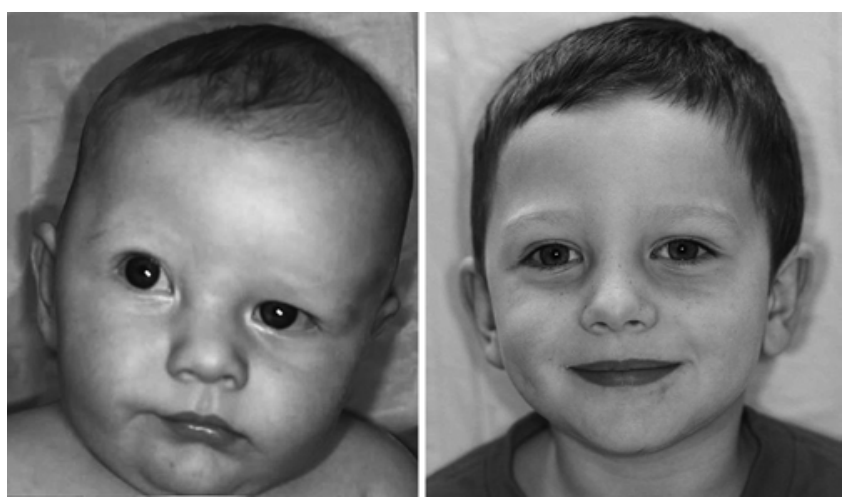

FIG. 7. Preoperative (left) and 3-year postoperative (right) photographs of a 3-month old boy presenting with right coronal synostosis. Left: Vertical dystopia with right orbit elevation, nasal deviation, and sagittal plane deviation are noted. This patient underwent an endoscopic craniectomy lasting 44 minutes, with an estimated blood loss of $10 \mathrm{ml}$, no blood transfusion, and a 1-day length of stay. Right: Full correction of the vertical dystopia and sagittal deviation has been achieved. There was no need for ocular corrective surgery.

spectively (Table 2). In a normal symmetric patient, these 2 measurements should be identical. In cases of plagiocephaly, the opisthocranion-frontozygomaticus distance will be less on the side of craniosynostosis. Preoperatively the mean difference between these 2 measurements was $10 \mathrm{~mm} \pm 3 \mathrm{~mm}$. The mean difference decreased over time to $8 \mathrm{~mm}$ at 3 months, $7.1 \mathrm{~mm}$ at 6 months, $6.2 \mathrm{~mm}$ at 9 months, $5.2 \mathrm{~mm}$ at 12 months, $3 \mathrm{~mm}$ at 24 months, and $1.5 \mathrm{~mm}$ at 36 months. Thus, advancement of the supraorbital-zygomatic rim complex was demonstrated over time to produce a small residual amount of asymmetry at 36 months (Fig. 10). Furthermore, advancement of the entire frontoorbital complex was documented with standard lateral radiographs, which were obtained immediately following surgery and at subsequent visits. These radiographs clearly demonstrated an increase in the osteotomy width over time and achievement of levels commensurate with the typical orbitofrontal advancement obtained with traditional open techniques (Fig. 11). One hundred thirteen patients (98\%) had supraorbital rim advancement of the involved orbit.

\section{Discussion}

Lannelongue in $1890^{20}$ and Lane in $1892^{19}$ were the first to describe surgical treatment of craniosynostosis using strip craniectomies of the involved sutures. Incomplete and poor results led surgeons to use more extensive procedures. Following the development of craniofacial surgery, Rougerie et al. used suturectomies and cranial vault reconstructive techniques. ${ }^{29}$ In Canada, Harold Hoffman championed lateral canthal advancement, ${ }^{8}$ which involved osteotomies along the orbital roof (behind the supraorbital rim) posterior and frontozygomatic suture; the advancement was held in place with a bone strut. This technique attempted to address and correct the ipsilateral frontal plagiocephaly but did not address the contralateral compensatory changes that occur with synostosis. The team at the University of Virginia (John Jane, John Persing, and 


\section{Endoscopy-assisted treatment of coronal synostosis}
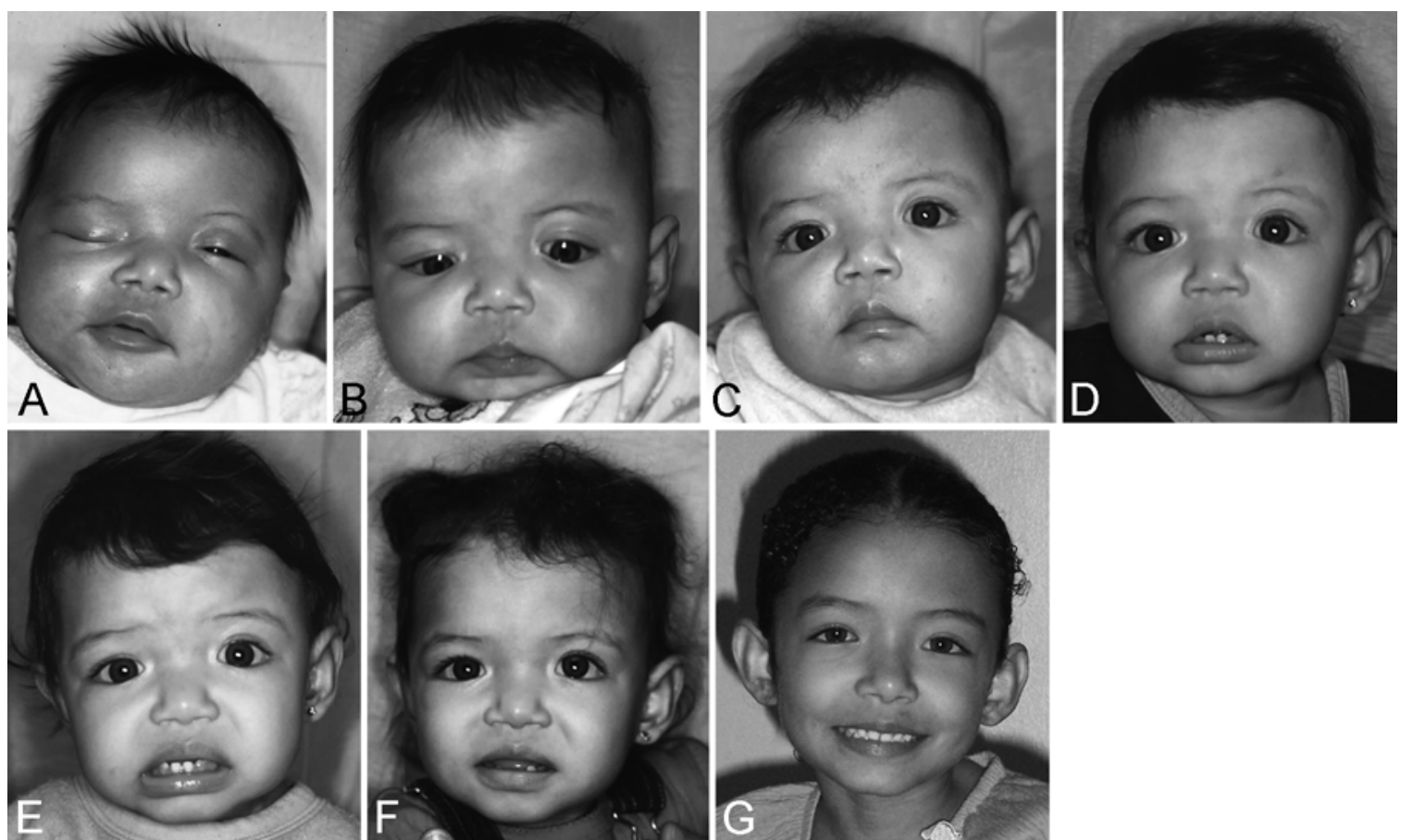

Fig. 8. Views of a girl who presented at 2.5 months of age with left coronal synostosis, dystopia, and sagittal plane deviation. The surgery took 30 minutes. Estimated blood loss was $15 \mathrm{ml}$, there were no blood transfusions or complications, and the patient had a 1-day length of stay. A-E: Preoperative (A) and 1-month (B), 3-month (C), 6-month (D), and 8-month (E) postoperative views. Early correction of nasal deviation and sagittal imbalance is observed at 3 months $(C)$. F and G: One-year postoperative view $(F)$ shows marked improvement of vertical dystopia and straightening of the face alignment. Six-year postoperative view $(G)$ demonstrates that correction continues to take place long after the procedure. The patient has normal features with complete correction of the preoperative deformities.

Milton Edgerton) vehemently argued in favor of addressing the need for correction of the contralateral orbit. ${ }^{4-6,9,25}$ Hoffman, Renier, and Marchac did not believe that there was a need to do so. As time went on, it became evident that the unilateral approach was not sufficient enough to correct the problem and a bilateral approach was, indeed, needed. Persing et al. were the first to publish on the rules governing the calvarial changes that occur following a single suture synostosis. ${ }^{25}$ Whitaker et al. ${ }^{31}$ in Philadelphia and Marchac and Renier ${ }^{23,24}$ added techniques to the bilateral correction of the deformity. These techniques involve bifrontal craniotomies, removal of both supraorbital rims (orbital bandeau), and advancement of the recessed side to obtain immediate forehead and orbital correction. Many

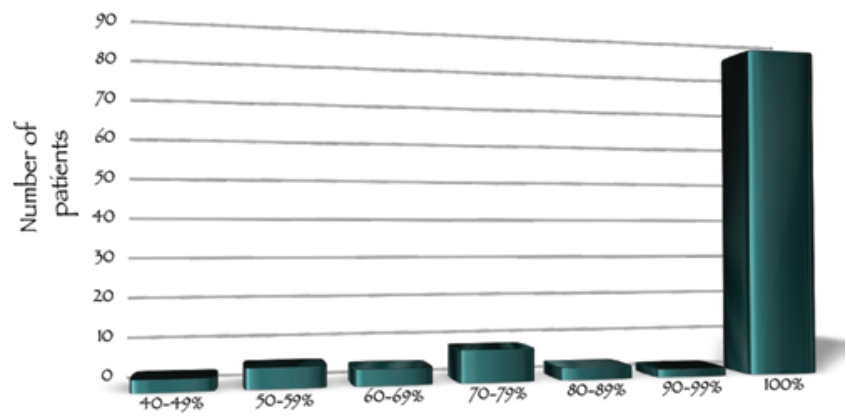

FIG. 9. Histogram showing the total number of patients who reached different levels of correction from the preoperative midsagittal plane deviation. One hundred percent correction means that the vertex, nasion, and gnathion are all aligned on a single midsagittal line. other variations have been introduced and include threequarter orbital osteotomies with reshaping, and repositioning of the orbital rims and forehead..$^{26,27}$

Calvarial remodeling techniques are typically associated with significant blood loss, blood transfusions, postoperative swelling, and pain, as well as prolonged (4-6 day) hospital stays. Overall, the immediate postoperative results are excellent, but close and careful longterm follow-up of these patients indicates progressive changes leading to poor results. Restriction of forward growth of the anterior skull base skeleton commonly leads to the development of progressive turricephaly. Not infrequently, the patient's forehead demonstrates an uneven surface with many noticeable "bumps, lumps, and depressions." Anchoring devices such as wires, titanium plates, and screws are often subcutaneously visible, palpable, and occasionally painful and tender. Furthermore, because the patients are typically operated on during ages closer to 1 year, skull base deformities such as vertical dystopia and nasal deviation are not properly corrected and persist into adulthood. Additionally, the well-known phenomenon of titanium plate and screw migration into the dura and brain parenchyma can be observed with this type of operation. . $^{3,17,18}$

Review of normal cranial and brain growth in children demonstrates extremely rapid increases in brain volume and cranial capacity. At birth, average brain volume is 330 $\mathrm{cm}^{3}$, which increases to $675 \mathrm{~cm}^{3}(+104 \%)$ by 9 months and $960 \mathrm{~cm}^{3}(+291 \%)$ by the third year of life. At birth, cranial 
D. F. Jimenez and C. M. Barone

TABLE 2: Anthropometric measurement record ${ }^{*}$

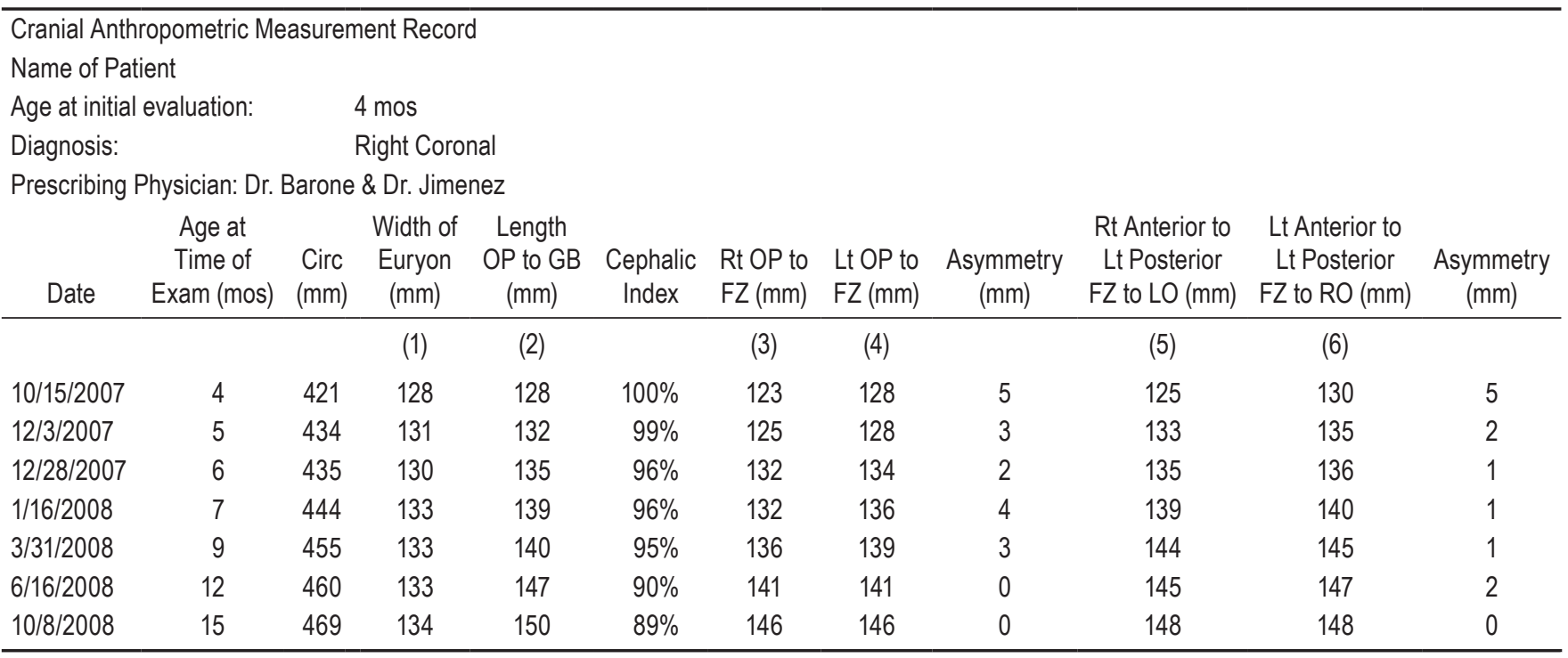

* Anthropometric measurement record of a patient shows the multiple measurements that are taken with each clinic visit. Asymmetry and its correction are documented along with other cranial parameters. Photograph below is included in the form and indicates the various measurements. Circ $=$ head circumference; Exam = examination; $\mathrm{FZ}$ = frontozygomaticus; $\mathrm{GB}=$ glabella; $\mathrm{LO}=$ left occipital; $\mathrm{OP}=$ opisthocranion; $\mathrm{RO}=$ right occipital.

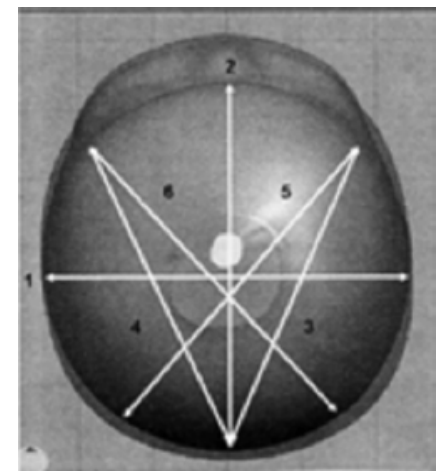

capacity is $350 \mathrm{~cm}^{3}$ and increases to $925 \mathrm{~cm}^{3}(+165 \%)$ by 9 months and $1225 \mathrm{~cm}^{3}(+350 \%)$ by year 3 . We used this basic developmental principle (very rapid brain growth during the first 2 years of life) to achieve normocephaly in infants affected by deformational changes secondary to unilateral coronal craniosynostosis.

Although the creation of customized helmets is labor intensive and requires meticulous care, their use helps to correct these deformities and plays a vital role in achieving proper correction. It is emphasized that these helmets do not constrict brain growth, but rather direct the direction of the growth vector forces. Head circumference growth in all patients was charted and measured at each clinic visit. Analysis of these measurements indicated that all patients' heads continued to grow along expected isocurves and there were no cases of drop off or brain growth restriction. The contralateral frontal lobe/forehead is held in place while the ipsilateral plagiocephalic frontal bone is given extra space to grow. It is observed that the earliest correction occurs at the nasal bone; nasal deviation begins to correct within the first 3 months after surgery and almost universally corrects completely. The next deformity to undergo correction is vertical dystopia (Fig. 12). The brain that was held superiorly and posteriorly by the synostosed suture is then allowed to expand in an anterior-inferior direction, thereby lowering the ipsilateral orbit and moving forward the recessed supraorbital rim. The last area to correct is the recessed frontal bone, which may take several years (4-6) to fully correct (Fig. 13). In cases of early and severe deformity, cranial scoliosis and sagittal imbalance may be observed. Correction of this deformity often responds to our treatment approach. Treatment with a helmet should last between 10 and 12 months postoperatively, or sooner if adequate correction is achieved. The average child requires 3 helmets to obtain full correction. Close follow-up of the patient is necessary to prevent an unwanted head shape secondary to an improperly fitting helmet. Postoperative follow-up clinic visits were typically scheduled as follows: 1 week, 6-8 weeks, 5 months, 9 months, 12 months, and yearly thereafter.

Although the complication rate of this patient series is extremely low, care must be taken to avoid complications. In both cases in which there were dural tears, the 


\section{Endoscopy-assisted treatment of coronal synostosis}
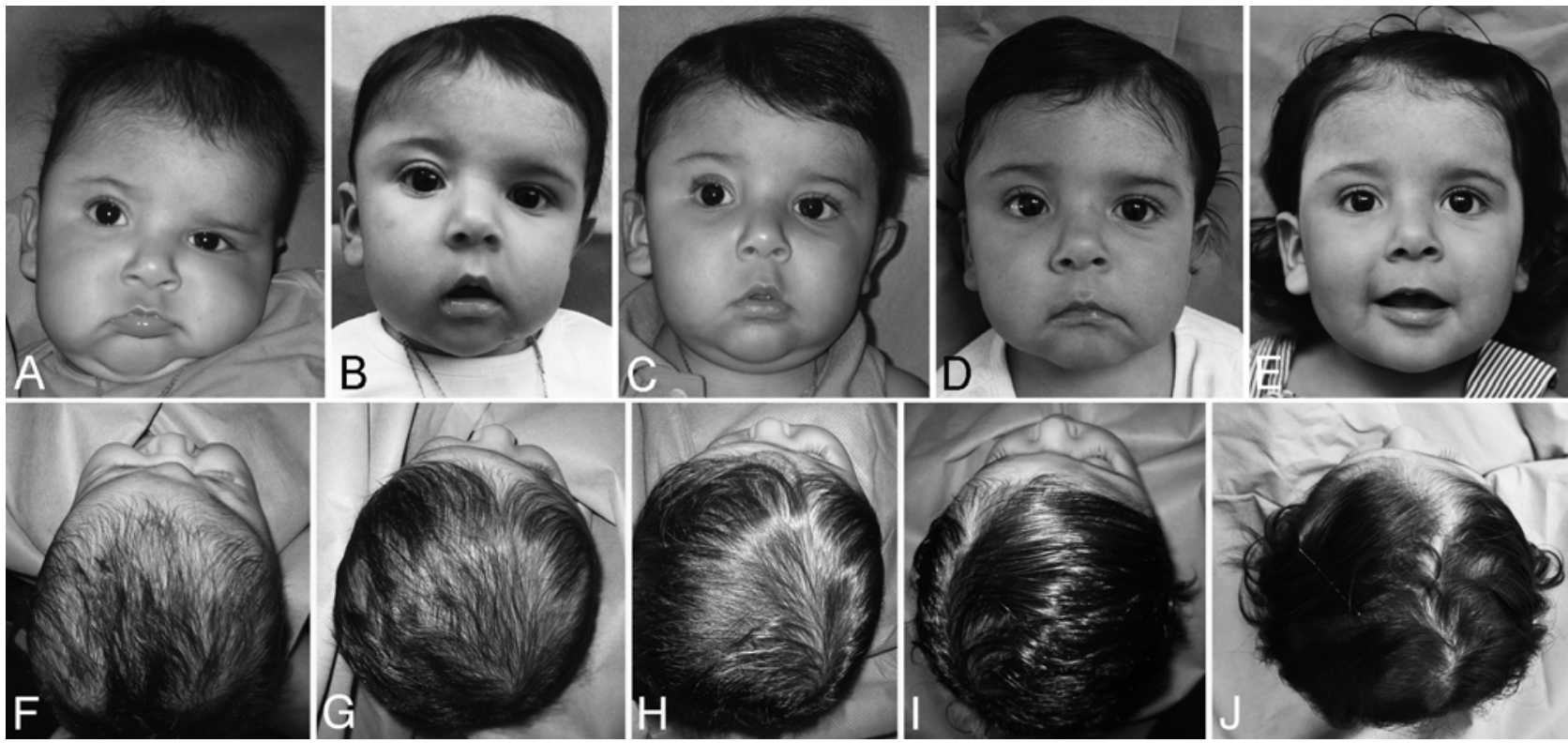

FIG. 10. Preoperative (A) and 2-month (B), 4-month (C), 7-month (D), and 1-year (E) postoperative views of a girl with right coronal synostosis who presented at 2 months of age with dystopia, sagittal deviation, and frontal plagiocephaly. The 1-year view (E) shows marked dystopia correction, slight nasal deviation, and full correction of sagittal plane deviation. Corresponding overhead views of this patient at the same time points $(\mathrm{F}-\mathrm{J})$ are also shown. Right frontal bone recession is observed with significant bone indentation above the supraorbital rim $(F)$. At 4-months postoperatively $(\mathrm{H})$ right frontal bone advancement is observed with the aid of the molding helmet. The 1-year postoperative view $(\mathrm{J})$ shows residual right-frontal plagiocephaly but with continued improvement, which is most often noted during the following several years.
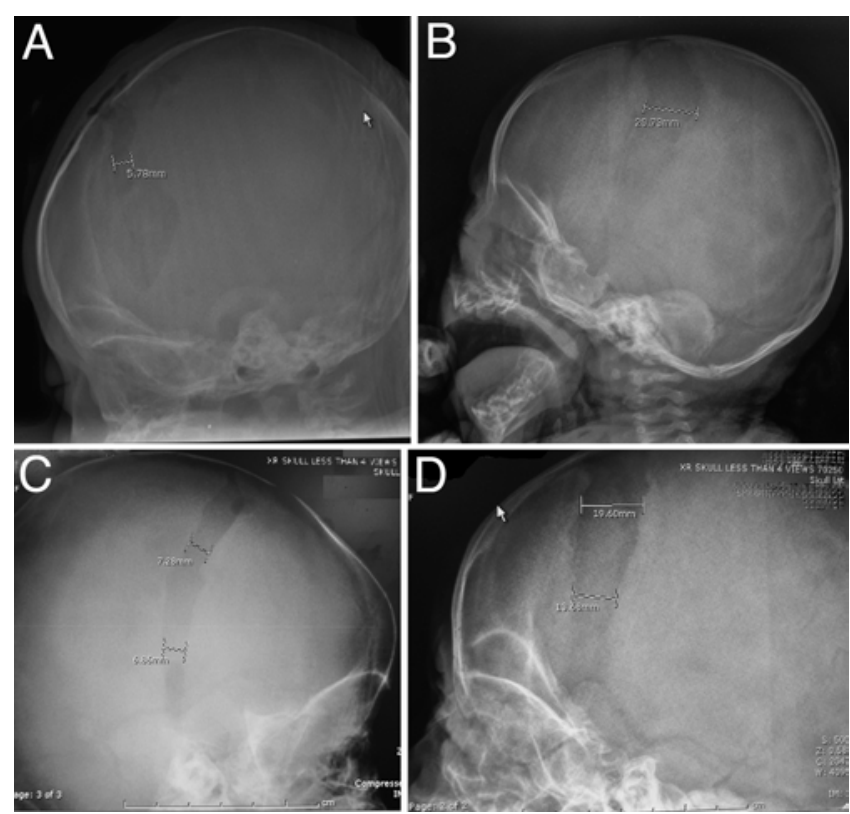

FIG. 11. Lateral skull radiographs in 2 patients demonstrating advancement of the entire frontoorbital complex. $\mathbf{A}$ and $\mathbf{B}$ : Radiograph of a 2-month old obtained immediately after surgery $(A)$ demonstrates a craniectomy measuring about $6 \mathrm{~mm} ; 3$ months after surgery (B) a radiograph shows that the frontal bone has advanced about $1.5 \mathrm{~cm}$, as evidenced by a craniectomy size of approximately $21 \mathrm{~mm}$. C and D: Radiograph of a 2-month old obtained immediately postoperatively (C) shows a craniectomy size of $7 \mathrm{~mm} ; 2$ months after surgery the craniectomy size has increased by at least $1 \mathrm{~cm}$ to $19.6 \mathrm{~mm}(\mathrm{D})$. osteotomies were performed using bone-cutting scissors close to the still-opened coronal suture at the base and without first taking care to visualize that the dura was fully separated from the overlying bone. In 1 case, the durotomy was sutured with 4-0 Nurolon through the same incision. In the second case, a small scalp incision was made over the tear that was located behind the sphenoid wing. Care must be taken to fully cauterize the diploe with monopolar electrocautery to prevent postoperative hematomas. Only 2 patients had scalp irritation that was secondary to contact dermatitis with the helmet lining. Removal of the helmet for 4 or 5 days, application of $0.5 \%$ hydrocortisone cream, and lining the helmet with leather successfully treated this problem.

It is often pointed out that strip craniectomies have been shown, in the past, not to provide adequate correction of the craniofacial deformities associated with coronal synostosis. We believe that the major difference with our approach is the use of the helmet following the early release of the stenosed suture. The strip craniectomy concept, while not new, is performed via a minimally invasive endoscopic approach that negates the need for a bicoronal scalp incision. This approach also decreases surgical time, tissue trauma, and blood loss. Care must be taken to obtain a full release from the anterior fontanelle all the way down to the squamosal suture; failure to do so will result in a less than optimal outcome. During our initial cases, we extended our bone resection anteriorly into the lesser wing of the sphenoid. However, there is no need to do so, and we currently resect the upper half of the suture but extend the craniectomy posteriorly and behind the open coronal suture. A $30^{\circ}$ rigid endoscope allows for visualization of 

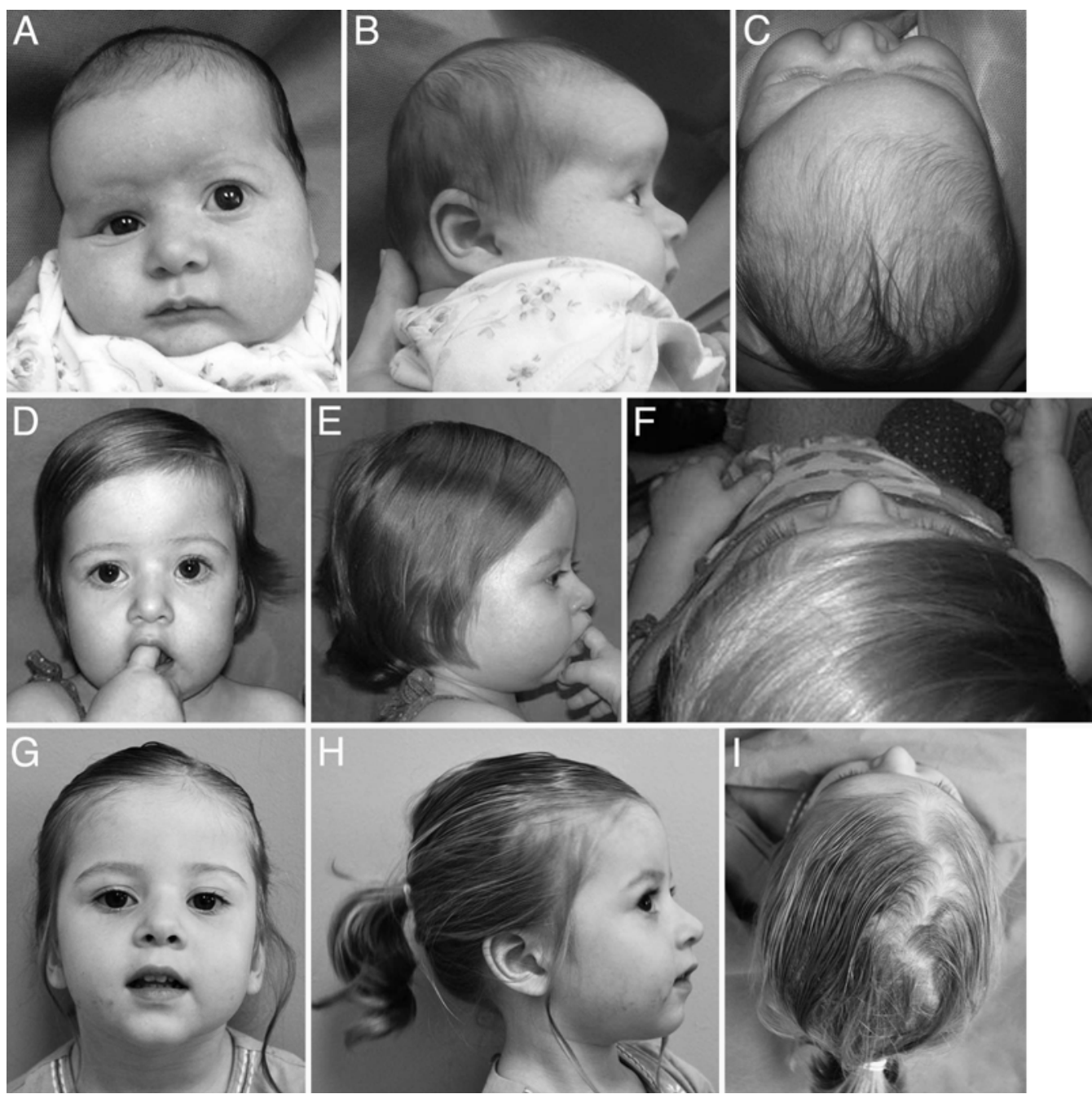

Fig. 12. Photographs showing correction in a girl with left coronal synostosis. A-C: Preoperative photographs. Lateral image (B) shows significant forehead bossing. D-F: Images obtained 1 year after surgery show significant correction has taken place. G-I: Images obtained 2.5 years after surgery illustrate correction of the vertical dystopia and midsagittal deviation. Note how forehead bossing was fully corrected without the need for frontal craniectomies or forehead advancement. Also note correction of frontal plagiocephaly and the attainment of a symmetric forehead.

the orbital roof and lesser sphenoid wing anteriorly and the middle meningeal artery and pterion posteriorly. Visualization of the lesser wing is useful for proper orientation.

We have noticed that the osteogenic capacity of the dura on the level of the coronal suture is significantly less than that of the vertex. During our initial cases, the osteotomies were 1-2 cm in width. With frontal bone advancement by the growing brain, the osteotomy is further distracted by more than $2 \mathrm{~cm}$, leading to a large gap that takes longer to ossify. Our current techniques call for an osteotomy between 5 and $7 \mathrm{~mm}$. When fully distracted several months later, the osteotomy can measure up to $30 \mathrm{~mm}$. We have had no problems with complete reossification with the smaller osteotomies, except for 1 patient whose defect continues to become smaller over time.

The goal of an open orbitofrontal advancement is to mobilize the frontal bone and orbital rims by approximately $2 \mathrm{~cm}$ using tongue-in-grove fixation techniques. We have been able to achieve similar orbital frontal advancements with our technique and without the need for extensive surgery. The distraction is achieved by the growing brain, which pushes the bone complex forward with the aid of the molding cranial orthosis. The results are corroborated with plain lateral radiographs (Fig. 11) and photographs. The chronological order of the deformity correction was as follows: 1) nasal deviation, 2) vertical dystopia, 3) sagittal deviation, and 4) frontal plagiocephaly.

Even following full reossification, the patient's plagiocephaly continues to correct as the years pass by. Early on, we considered endoscopic forehead augmentation through the same incision for patients who, although the dystopia and nasal deviation had corrected, continued to show persistent forehead retraction. However, as the children grew older, we noticed continued improvement and have not found a need to perform forehead augmentation; we are currently considering a frontal advancement in a 6-year-old with residual frontal asymmetry. In the older children, whose frontal sinuses have begun to develop, further improvement is observed. Another benefit 


\section{Endoscopy-assisted treatment of coronal synostosis}
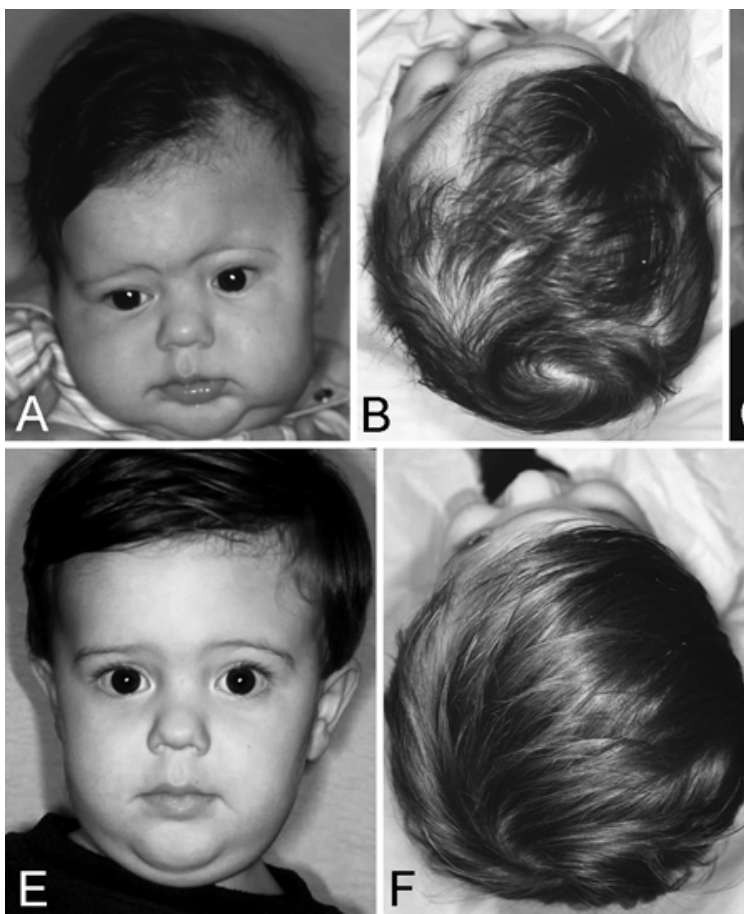
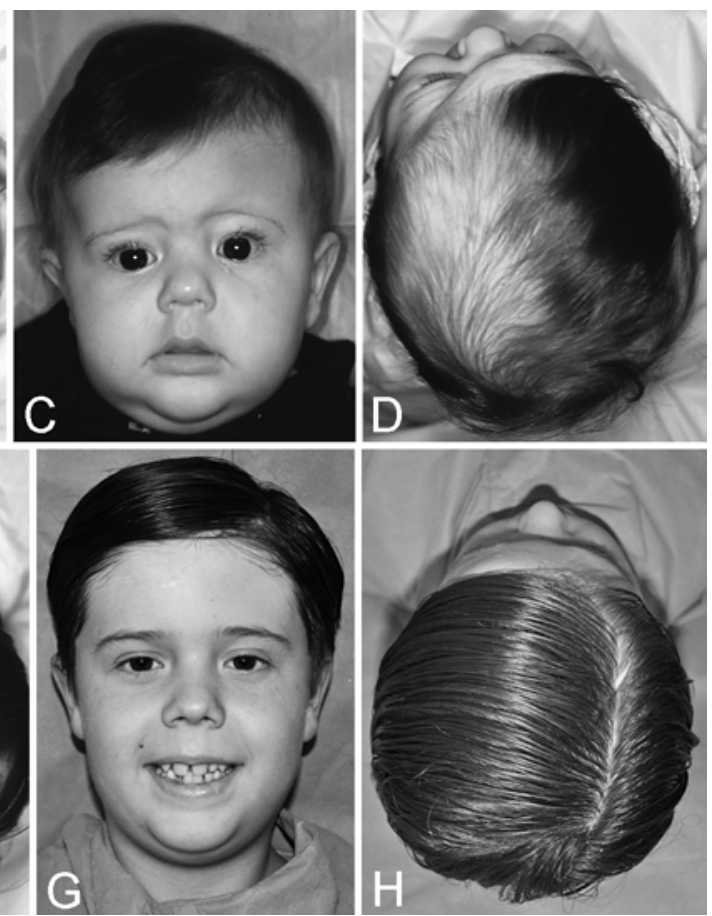

Fig. 13. Photographs showing correction in an infant boy with severe left coronal craniosynostosis, dystopia, and plagiocephaly. A and B: Preoperative images obtained at 3 months of age. $\quad \mathbf{C}-\mathrm{H}$ : Images obtained 3 months (C and D), 2 years (E and $\mathrm{F}$ ), and 8 years ( $\mathrm{G}$ and $\mathrm{H}$ ) after surgery. The patient has obtained full correction, including a symmetric forehead and normal facial morphology ( $\mathrm{G}$ and $\mathrm{H})$.

of our approach is that progenitor cells of the frontal sinus are not disrupted, as is the case with orbital bandeau advancement.

The best results were obtained in the youngest patients and those less than 3 months of age. Excellent results were also achieved in the group between 3 and 6 months of age, but fewer of these patients achieved 100\% correction of their deformities. Inconsistent results were obtained in the group between 6 and 9 months of age. If the deformities (dystopia, sagittal deviation) are not significant, very good correction can be achieved. However, those children with marked deformities in this age group did not attain correction as desired. Therefore, the goal should be to treat these children before 6 months of age and certainly preferably before 3 months.

Some of the most concerning side effects of unilateral coronal synostosis are the ophthalmological problems that develop before and after surgical treatment. Included among these are V-pattern strabismus, excyclotorsion, aniso-astigmatism, and amblyopia. The estimated incidence of V-pattern strabismus has been reported as $81 \%,{ }^{28} 50 \%$, and $57.6 \%{ }^{21}$ in different studies. In a recent study comparing the ophthalmological findings of endoscopic strip craniectomy versus frontoorbital advancement, MacKinnon et al..$^{22}$ found that the endoscopic craniectomy patients developed less severe V-pattern strabismus, excyclotorsion of the fundus, and range of aniso-astigmatisms. The authors argue for early treatment versus later frontoorbital advancement. The latter displaces the bandeau anteriorly after stripping free the periorbita, which causes the trochlea to fall further behind and can exacerbate the relative retropositioning of the superior oblique. The endoscopic craniectomy does not affect any of the muscular attachments and allows for proper orbital repositioning with maintenance of extraocular muscle balance. ${ }^{22}$ Arguments for earlier treatment are supported by Denis et al. ${ }^{2}$ who reported a decrease in the incidence of strabismus from $67 \%$ to $19 \%$ by decreasing the mean age of corrective frontoorbital advancement from 23 months to 5.6 months. In our series only $7(6.4 \%)$ of the 109 patients have required the need for surgical correction of strabismus (Fig. 14). Our results compare favorably with those of Gosain and colleagues ${ }^{7}$ who noted the need for strabismus correction in 7 (77.7\%) of 9 patients who underwent frontoorbital advancement; preexisting strabismus resolved spontaneously after frontoorbital advancement in only 1 of their 8 patients.

\section{Conclusions}

We have presented our 16-year experience treating infants with craniosynostosis using endoscopic suturectomies and postoperative orthotic therapy. Results indicate that our approach provides an excellent alternative for treating this group of patients. We believe that correction of the vertical dystopia, nasal deviation, and sagittal imbalance are the best results of this operation. Persistence of these deformities, often noted when the patients are operated on late (9-12 months of age), leads to lifetime disfigurement that is impossible to correct (with the exception of nasal deviation, which can be subsequently corrected with rhinoplasty). The brain is the driving force for the shape of the cranial and facial skeleton, and by releasing the stenosed suture early, the brain is allowed 


\section{F. Jimenez and C. M. Barone}
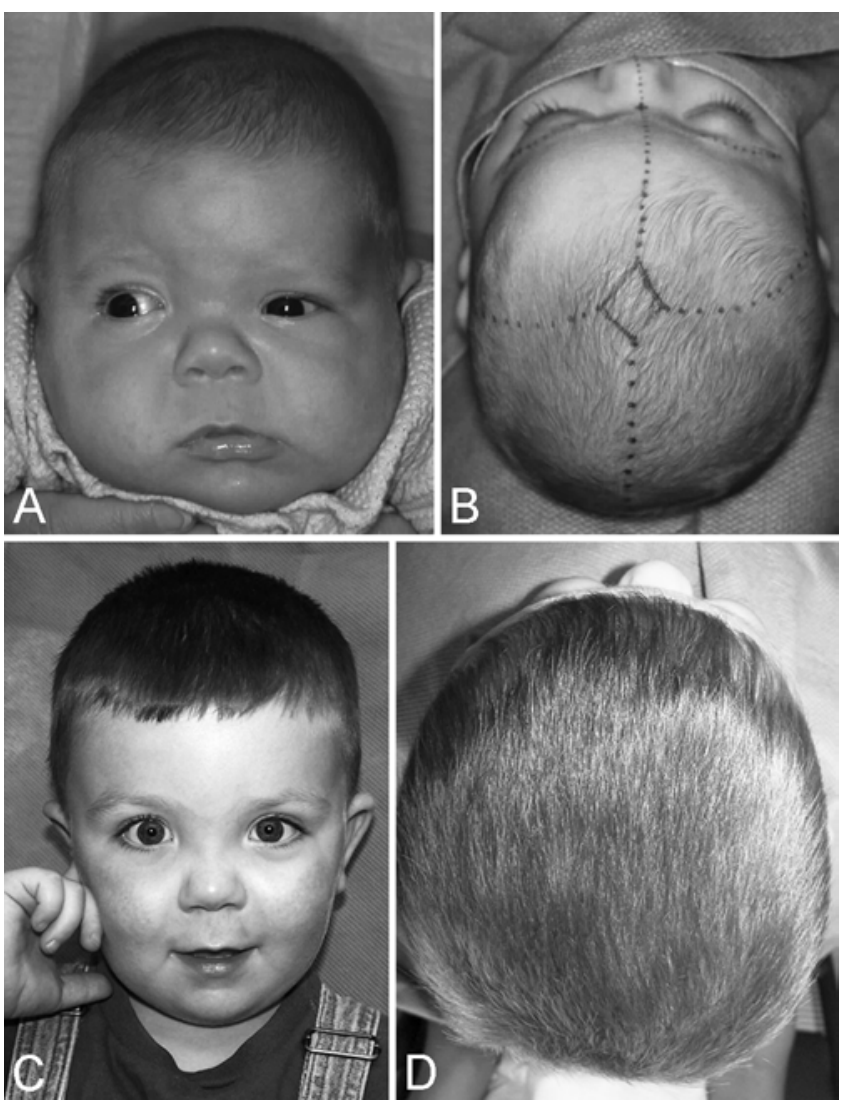

FIG. 14. Photographs showing correction in an infant boy with right coronal craniosynostosis, vertical dystopia, and plagiocephaly. A and B: Preoperative photos obtained at 2 months of age. Notice marked esotropia of the right eye associated with the vertical dystopia and plagiocephaly. C and D: Three years after surgery the patient shows normal eye alignment and ocular movement. The patient did not require ocular corrective surgery. Also note the forehead symmetry and balance.

to achieve normal morphology with the aid of the helmet. Our assertions are corroborated by plain radiographs, extensive photographic assessment, and most importantly, by long-term follow-up anthropometric testing. Besides the obvious cosmetic correction and restoration of craniofacial balance, our low rate of postoperative strabismus corrective surgery and high rate of normal ophthalmological findings attest to the excellent results obtained with this procedure in very young infants (Fig. 15). Endoscopic treatment of coronal synostosis is a safe, cost-effective, and highly efficacious way to treat this condition, and this option should be considered and offered to parents of children affected by the condition.

\section{Disclosure}

The authors report no conflict of interest concerning the materials or methods used in this study or the findings specified in this paper.

Author contributions to the study and manuscript preparation include the following. Conception and design: both authors Acquisition of data: both authors. Analysis and interpretation of data: both authors. Drafting the article: Jimenez. Critically revising the article: both authors. Reviewed submitted version of manuscript:

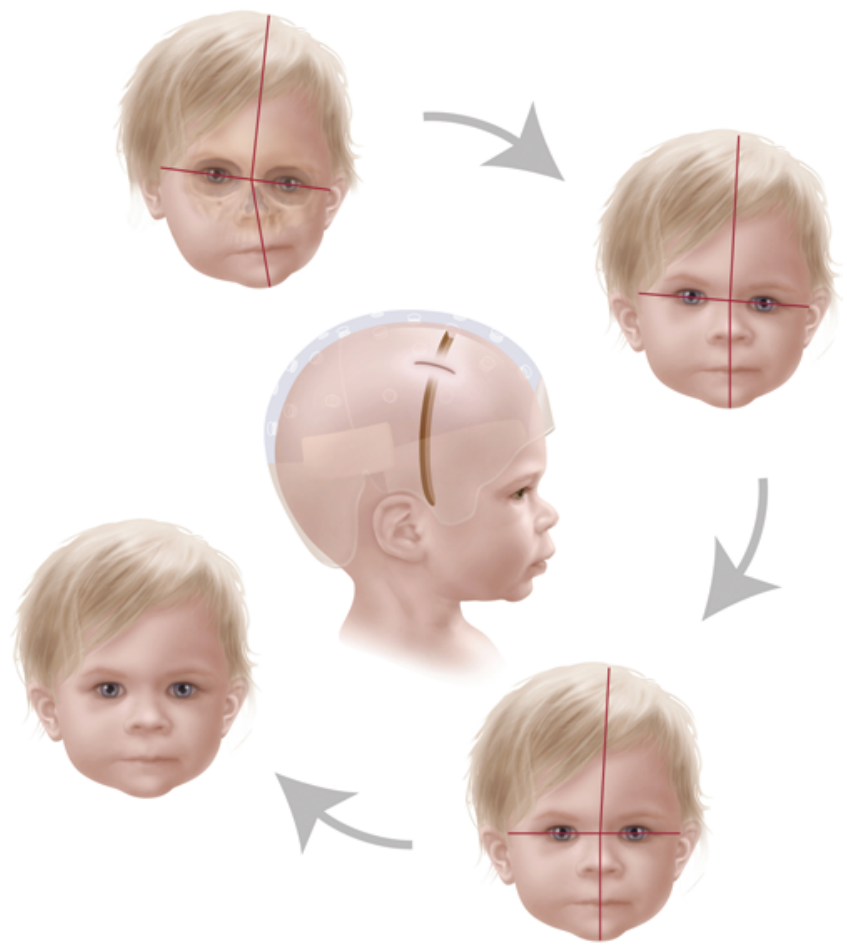

FIG. 15. Artist's rendition of progressive correction of right coronal synostosis following endoscopic craniectomy. Initial image (upper left) shows preoperative deformities with vertical dystopia and sagittal deviation. Progressive changes include early descent of the right orbit and early correction of the nasal deviation (upper right). Further improvement lends to correction of the vertical dystopia (lower right), to ultimately end with sagittal alignment and normalization of the patient's facial features (lower left).

both authors. Approved the final version of the manuscript on behalf of both authors: Jimenez. Statistical analysis: both authors.

\section{Acknowledgments}

The authors wish to thank Wai Choi, R.N., for her dedication to our patients and their families. All illustrations were produced by Matthew Holt, medical illustrator.

\section{References}

1. Barone CM, Jimenez DF: Endoscopic craniectomy for early correction of craniosynostosis. Plast Reconstr Surg 104: 1965-1975, 1999

2. Denis D, Genitori L, Bolufer A, Lena G, Saracco JB, Choux M: Refractive error and ocular motility in plagiocephaly. Childs Nerv Syst 10:210-216, 1994

3. Duke BJ, Mouchantat RA, Ketch LL, Winston KR: Transcranial migration of microfixation plates and screws. Case report. Pediatr Neurosurg 25:31-35, 1996

4. Edgerton MT, Jane JA, Berry FA: Craniofacial osteotomies and reconstructions in infants and young children. Plast Reconstr Surg 54:13-27, 1974

5. Edgerton MT, Jane JA, Berry FA, Fisher JC: The feasibility of craniofacial osteotomies in infants and young children. Scand J Plast Reconstr Surg 8:164-168, 1974

6. Edgerton MT, Jane JA, Berry FA, Marshall KA: New surgical concepts resulting from cranio-orbito-facial surgery. Ann Surg 182:228-239, 1975 


\section{Endoscopy-assisted treatment of coronal synostosis}

7. Gosain AK, Steele MA, McCarthy JG, Thorne CH: A prospective study of the relationship between strabismus and head posture in patients with frontal plagiocephaly. Plast Reconstr Surg 97:881-891, 1996

8. Hoffman HJ, Mohr G: Lateral canthal advancement of the supraorbital margin. A new corrective technique in the treatment of coronal synostosis. J Neurosurg 45:376-381, 1976

9. Jane JA, Edgerton MT, Futrell JW, Park TS: Immediate correction of sagittal synostosis. J Neurosurg 49:705-710, 1978

10. Jimenez DF, Barone CM: Early treatment of anterior calvarial craniosynostosis using endoscopic-assisted minimally invasive techniques. Childs Nerv Syst 23:1411-1419, 2007

11. Jimenez DF, Barone CM: Endoscopic assisted wide vertex craniectomy, "barrel-stave" osteotomies, and postoperative helmet molding therapy in the early management of sagittal suture craniosynostosis. Neurosurgical Focus 9(3):e2, 2000

12. Jimenez DF, Barone CM: Endoscopic craniectomy for early surgical correction of sagittal craniosynostosis. J Neurosurg 88:77-81, 1998

13. Jimenez DF, Barone CM: Multiple-suture nonsyndromic craniosynostosis: early and effective management using endoscopic techniques. Clinical article. J Neurosurg Pediatr 5:223-231, 2010

14. Jimenez DF, Barone CM, Cartwright CC, Baker L: Early management of craniosynostosis using endoscopic-assisted strip craniectomies and cranial orthotic molding therapy. Pediatrics 110:97-104, 2002

15. Jimenez DF, Barone CM, McGee ME, Cartwright CC, Baker CL: Endoscopy-assisted wide-vertex craniectomy, barrel stave osteotomies, and postoperative helmet molding therapy in the management of sagittal suture craniosynostosis. J Neurosurg 100 (5 Suppl Pediatrics):407-417, 2004

16. Johnson JO, Jimenez DF, Barone CM: Blood loss after endoscopic strip craniectomy for craniosynostosis. J Neurosurg Anesthesiol 12:60, 2000 (Letter)

17. Joshi SM, Witherow H, Dunaway DJ, Hayward RD: The danger of using metallic plate and screw fixation in the young. $\mathbf{B r}$ J Neurosurg 20:330, 2006

18. Kosaka M, Miyanohara T, Wada Y, Kamiishi H: Intracranial migration of fixation wires following correction of craniosynostosis in an infant. J Craniomaxillofac Surg 31 15-19, 2003

19. Lane LC: Pioneer craniectomy for relief of mental imbecility due to premature sutural closure and microcephalus. JAMA 18:49-50, 1892

20. Lannelongue M: De la craniectomie dans la microcéphalie. Compt Rend Seances Acad Sci 50:1382-1385, 1890
21. Macintosh C, Wall S, Leach C: Strabismus in unicoronal synostosis: ipsilateral or contralateral malformations. J Craniofac Surg 18:465-469, 2007

22. MacKinnon S, Rogers GF, Gregas M, Proctor MR, Mulliken JB, Dagi LR: Treatment of unilateral coronal synostosis by endoscopic strip craniectomy or fronto-orbital advancement: ophthalmologic findings. J AAPOS 13:155-160, 2009

23. Marchac D: Radical forehead remodeling for craniostenosis. Plast Reconstr Surg 61:823-835, 1978

24. Marchac D, Renier D: [The "floating forehead". Early treatment of craniofacial stenosis.] Ann Chir Plast 24:121-126, 1979 (Fr)

25. Persing JA, Edgerton MT, Jane JA (eds): Scientific Foundations and Surgical Treatment of Craniosynostosis. Baltimore: Williams \& Wilkins, 1989

26. Posnick JC: Unilateral coronal synostosis (anterior plagiocephaly): current clinical perspectives. Ann Plast Surg 36: 430-447, 1996

27. Posnick JC (ed): Posterior plagiocephaly: unilateral lambdoid synostosis and skull molding, in: Craniofacial and Maxillofacial Surgery in Children and Young Adults. Philadelphia: WB Saunders, 2000, Vol 1, pp 231-247

28. Robb RM, Boger WP III: Vertical strabismus associated with plagiocephaly. J Pediatr Ophthalmol Strabismus 20:58-62, 1983

29. Rougerie J, Derome P, Anquez L: [Craniostenosis and craniofacial dysmorphism. Principles of a new method of treatment and its results.] Neurochirurgie 18:429-440, 1972 (Fr)

30. Tobias JD, Johnson JO, Jimenez DF, Barone CM, McBride DS Jr: Venous air embolism during endoscopic strip craniectomy for repair of craniosynostosis in infants. Anesthesiology 95:340-342, 2001

31. Whitaker LA, Schut L, Kerr LP: Early surgery for isolated craniofacial dysostosis. Plast Reconstr Surg 60:575-581, 1977

Manuscript submitted May 10, 2011.

Accepted April 25, 2013.

Please include this information when citing this paper: published online June 28, 2013; DOI: 10.3171/2013.4.PEDS11191.

Address correspondence to: David F. Jimenez, M.D., 7703 Floyd Curl Dr., MC 7843, San Antonio, TX 78229. email: jimenezd3@ uthscsa.edu. 